ORIGINAL ARTICLE

PRACA ORYGINALNA

\title{
PATHOMORPHOLOGICAL CHARACTERISTICS AND IMMUNOHISTOCHEMICAL FEATURES OF PLACENTAE FROM HIV-POSITIVE PREGNANT WOMEN WITH FETAL GROWTH RETARDATION
}

D0I: 10.36740/WLek202002101

\author{
Serhii E. Savchenko, Olena 0. Dyadyk, Kyrylo V. Chaika, Ludmila M. Onyshchyk, Ludmila I. Vorobey, \\ Roman V. Zhykharskyi, Volodymyr P. Bondaruk \\ SHUPYK NATIONAL MEDICAL ACADEMY OF POSTGRADUATE EDUCATION, KYIV, UKRAINE
}

\begin{abstract}
The aim: To study the pathomorphological characteristics and immunohistochemical features of placentae from human immunodeficiency virus-positive (HIV-positive) pregnant women with FGR.

Materials and methods: The study material was 32 placentae, including 12 placentae from HIV-positive pregnant women with FGR (study group), 10 placentae from HIVpositive pregnant women without FGR (comparison group) and 10 placentae from HIV-negative women with physiological pregnancy (control group). An immunohistochemical study was performed using monoclonal antibodies (MCA) against CD31+ and vascular endothelial growth factor (VEGF).

Results: Pathomorphologic changes of the placentae from HIV-positive pregnant women with FGR were characterized by edema in the umbilical cord tissue, partial dissection of the vascular wall fibers, dysmucoidosis; intracellular edema and hemorrhage in the fetal membrane tissues. In the placentae tissue it was found marked manifestations of degenerative changes in the form of the areas of fibrinoid necrosis, pronounced manifestations of dysmucoidosis, vacuolation of the villi stroma, an increase in the number of avascular villi and immature villi of small caliber with the phenomena of syncytiotrophoblast focal hyperplasia.

An immunohistochemical study with MCA against CD31+ revealed the expression (optical density) of the vascular endothelial cells up to 2 points, and the expression level up to 3 points in the isolated areas with the appearance of the expression on the villi surface and in their thickness. During immunohistochemical studies with VEGF the expression level and its optical density increased up to 2-3 points, in some areas the expression of deposits were detected on the villi surface, in their thickness and in the intervillous space. Conclusions: The comparative pathomorphological and immunohistochemical study of the placentae demonstrated more significant changes in the group of HIV-positive pregnant women with FGR. In the placentae of HIV-positive pregnant women with FGR immunohistochemical examinations revealed a high level of CD31+ and VEGF expression.
\end{abstract}

KEY WORDS: HIV, pregnancy, fetal growth retardation, placentae, morphology

Wiad Lek. 2020;73(2):215-219

\section{INTRODUCTION}

Since 2018 the total number of HIV-positive people reached 36.9 million, including 35.1 million of adults and 1.8 million of children under 15 years old. About 7000 young women of 15-24 years old are HIV infected per week. It is known that the results of HIV testing of pregnant women reflect the prevalence of HIV in the general population of the country. According to the Information bulletin No. 49 «HIV-infection in Ukraine» the level of HIV infection of pregnant women based on the results of primary testing has remained unchanged for the period from 2015 to 2017 (2015 - 0.33\%, $2016-0.32 \%, 2017-0.33 \%)$ [1].

In infectious pathology, including HIV, the placental function is affected, which lead to the development of placental dysfunction [2]. Placental dysfunction is one of the most common pathological syndromes in obstetrics, occurs in 17-35\% of pregnant women and manifested by miscarriage, preeclampsia, fetal distress, antenatal fetal death and FGR [3]. The frequency of placental dysfunction in HIV-positive pregnant women is $50-60 \%$ [4].
Placental dysfunction has a multifactorial etiology and is caused by morpho-functional changes and adaptation-homeostatic reactions of the placenta and the fetus, which leads to the disruption of its growth and development rates. Disruption of one of the links of physiological adaptation of the maternal organism to pregnancy leads to maladaptation, which can be manifested by FGR [5].

In modern obstetrics much attention is paid to growth factors and to study their role in the obstetric complications development. Growth factors are biologically active polypeptides which effect on the placental growth and development, control the processes of proliferation, cellular differentiation and programmed cell death (apoptosis) [6]. By participating in the processes of placental formation, they contribute to the normal functioning of the uterine-placental complex. Angiogenic growth factors such as placental growth factor and VEGF have the greatest importance in the diagnosing of placental dysfunction and FGR [7]. 
VEGF is a potent angiogenic protein, a potential mitogen for vascular epithelium, which effect on vascular permeability and is involved in neovascularization processes in pathological conditions $[6,8]$. VEGF stimulates activity, migration and proliferation of the endothelial cells. The most sensitive marker of the latter is CD31+, known as PECAM-1 (platelet endothelial cell adhesion molecule-1) $[9,10]$.

Placenta is the main crucial organ for ensuring the vital activity of the fetus, morphological changes of which can lead to pregnancy complications, such as FGR. Placenta is a very important diagnostic object with high information potential [11].

Further study of pathomorphological features of the placenta using modern markers will make it possible to discover new pathogenetic mechanisms of FGR, and will also make it possible in the future to create more effective methods of prevention of the specified pathology.

\section{THE AIM}

To study the pathomorphological characteristics and immunohistochemical features of placentae from HIV-positive pregnant women with FGR.

\section{MATERIALS AND METHODS}

The study was performed in the maternity consulting centre and obstetric infectious department of the Kyiv City Center of Reproductive and Perinatal Medicine, which is the clinical bases of the Department of Obstetrics, Gynecology and Reproductology, in conjunction with the Department of Pathological and Topographic Anatomy of the Shupyk National Medical Academy of Postgraduate Education.

The study material was 32 placentae, including 12 placentae from HIV-positive pregnant women with FGR (study group), 10 placentae from HIV-positive pregnant women without FGR (comparison group) and 10 placentae from HIV-negative women with physiological pregnancy (control group).

Macroscopic and microscopic examinations of the placentae were performed according to the standard protocol (the order of the Ministry of Health of Ukraine No. 417 of August 19, 2004 «On improvement of pediatric pathoanatomical service»).

At pathomorphological examination material was sampled from the different areas of umbilical cord, fetal membranes and placental tissue, and fixed in a $10 \%$ solution of neutral buffered formalin (pH 7.4) for 24-36 hours. From paraffin blocks on the rotary microtome HM 325 (ThermoShandon, England) the serial histological slides 4-5 $\mu \mathrm{m}$ were cut, and then stained with hematoxylin and eosin [12].

In all cases the immunohistochemical examinations were performed to determine the status of the placental vascular component. For high-temperature processing of antigen epitopes the citrate buffer with $\mathrm{pH} 6$ and EDTA buffer (pH8) were applied. MCA against VEGF (clone RB-9031-PO) and CD31+ (clone JC/70A) were used to evaluate the vascular component and vascular endothelium state. UltraVisionQuanto HRP detection system and Quanto DAB chromogen (ThermoFisherScientific, USA) were used $[13,14]$.

Positive expression was evaluated by optical density scale (qualitative score) from 1 to 3 points, and localization and prevalence of the positive reaction were also taken into account. The sign rating system $(+/-)$ was applied. The $« 0$ points» corresponded to the lack of the reaction, «1 point» - mild expression, «2 points» - moderate expression, «3 points» - marked expression. A detection color scale was used to estimate the staining intensity of the deposits [10, 12]. The staining intensity scale was created on the basis of the degree of relationship and intensity of black/white colors, and this scale was adapted for the estimating of intensity.

Microscopic examination and photo reporting were performed using ZEISS (Germany) optical microscope with AxioImager.A2 data processing system with $5 \mathrm{x}, 10 \mathrm{x}$, 20x, 40x magnification of object glasses, binoculars 1.5 and eyepiece 10 with an ERc 5s camera.

\section{RESULTS}

In the control group macroscopically the placentae had an oval shape in $70 \%$ of cases, and a rounded shape in 30\% of cases. The thickness and weight of the placenta were $3.6 \pm 0.2 \mathrm{~cm}$ and $493 \pm 17.6 \mathrm{~g}$ respectively. The central umbilical cord insertion sites were observed in 8 cases, the marginal in 2 . In all cases the umbilical cord had three vessels.

The maternal surface of placentae had dark red color. At pathomorphological examination $30.0 \%$ of cases revealed the following changes: umbilical cord tissue had mild edema of Wharton's jelly and focal manifestations of dysmucoidosis. The vascular component was without pathological changes. The tissue of the membranes had moderate manifestations of edema and isolated foci of dysmucoidosis, plethora areas and small hemorrhages. In the tissue of mature placentae there were normoformed villi, plethora areas of the blood vessels and intervillous space. Erythrostasis can be observed in some vessels of the villi. In most cases the small areas of fibrinoid necrosis of the villi and small foci of syncytiotrophoblastic hyperplasia were observed. Manifestations of dysmucoidosis were mild and mainly observed in the peripheral areas of placentae.

The immunohistochemical examinations with MCA against CD31+ revealed a mild (focal) expression of CD31+ positive cells of the vascular endothelium with staining intensity of 1 point, mainly observed in the areas of fibrinoid necrosis and dysmucoidosis (fig. 1).

In the vessel walls and on the villi surface in the areas of secondary placental tissue changes the expression of VEGF deposits was characterized by low staining intensity of 1 point (fig. 2).

In pathomorphological examination of the placentae from the HIV-positive pregnant women (comparison group) macroscopically they had an oval shape in $60 \%$ of cases and round shape in $40 \%$ of cases. The thickness and 


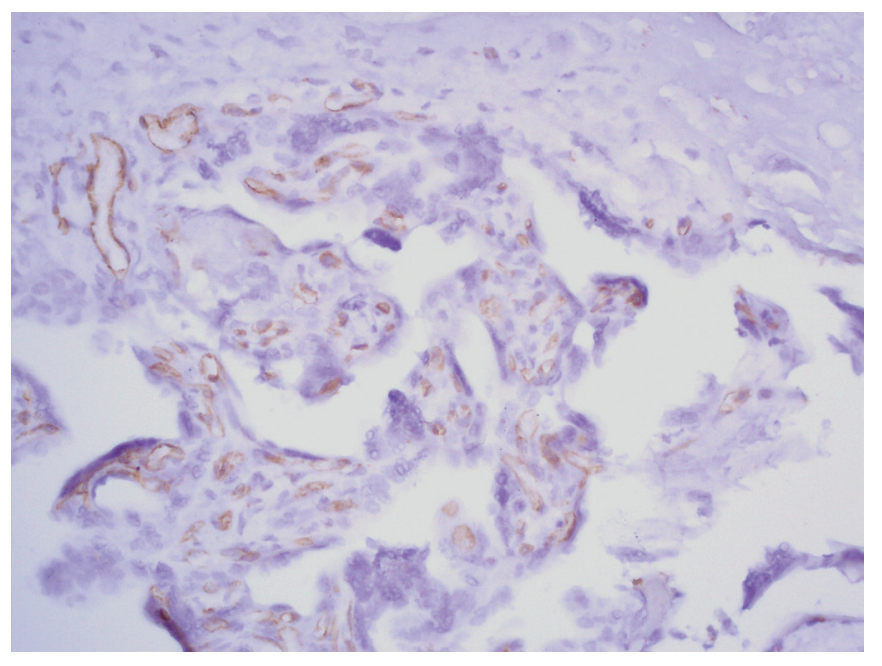

Fig 1. Control group. In placental tissue there is focal mild expression of endothelial cells with staining intensity of 1 point. Immunohistochemical reaction with MCA against $\mathrm{CD} 31+, \times 100$.

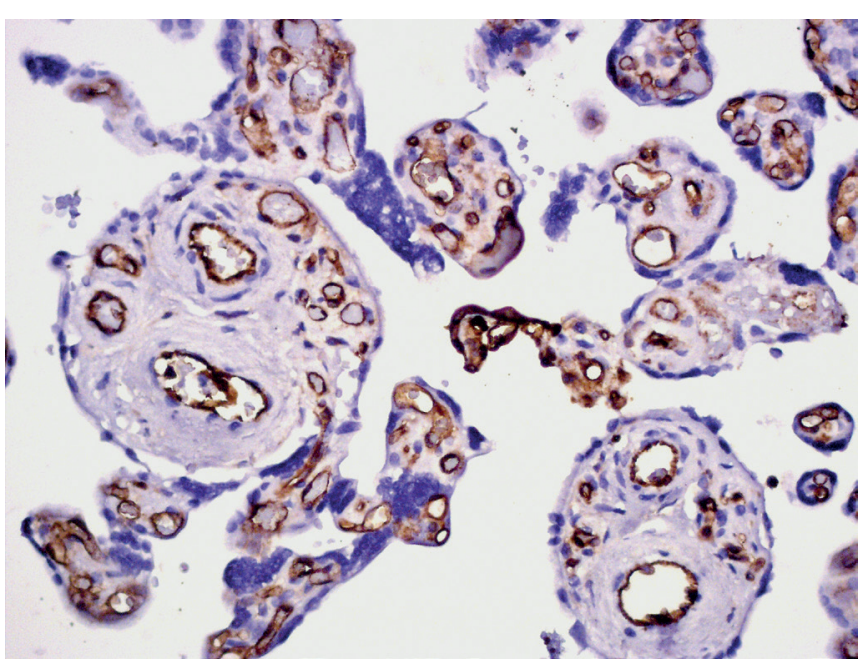

Fig. 3. Comparison group. In villi of different calibers there is the expression of positive endothelial cells, which form continuous chains that fill the entire perimeter of the vessel wall. Immunohistochemical reaction with MCA against CD31+, $\times 200$.

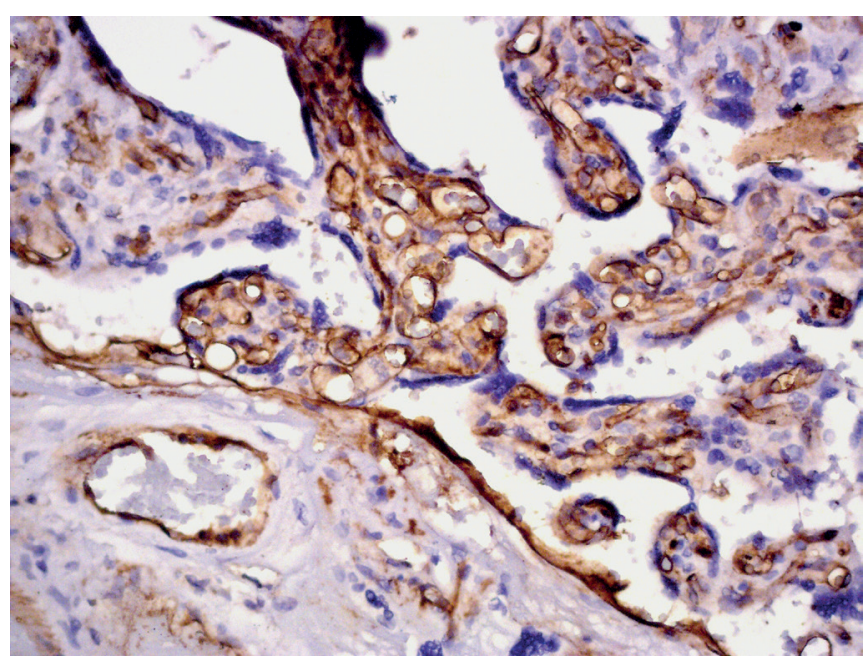

Fig. 5. Study group. In the placental tissue there is expression of the vascular marker CD31+ on the villi surface and in their thickness with staining intensity of 3 points. Immunohistochemical reaction with MCA against CD31+, $\times 200$.

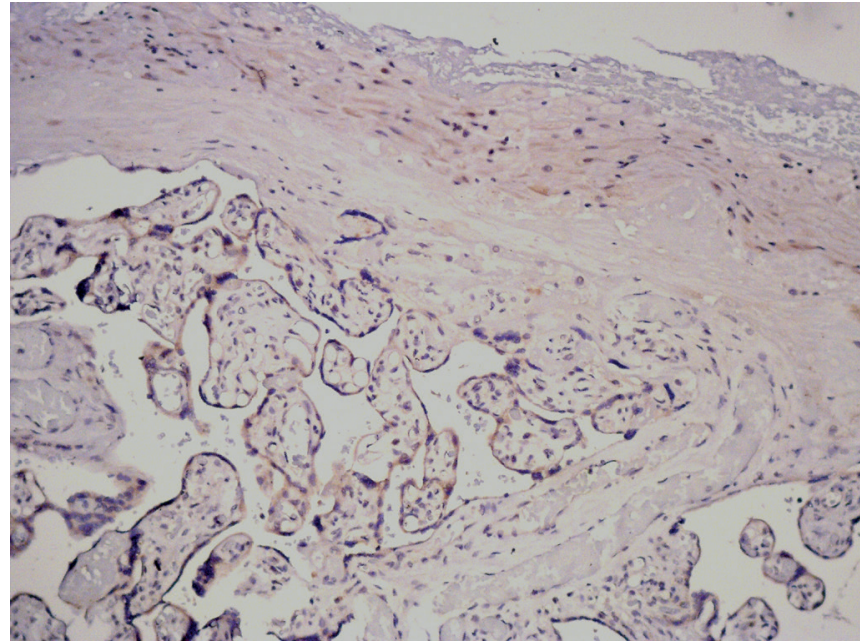

Fig. 2. Control group. In placental tissue there are small deposits with low staining intensity of 1 point. Immunohistochemical reaction with MCA against VEGF, $\times 100$.

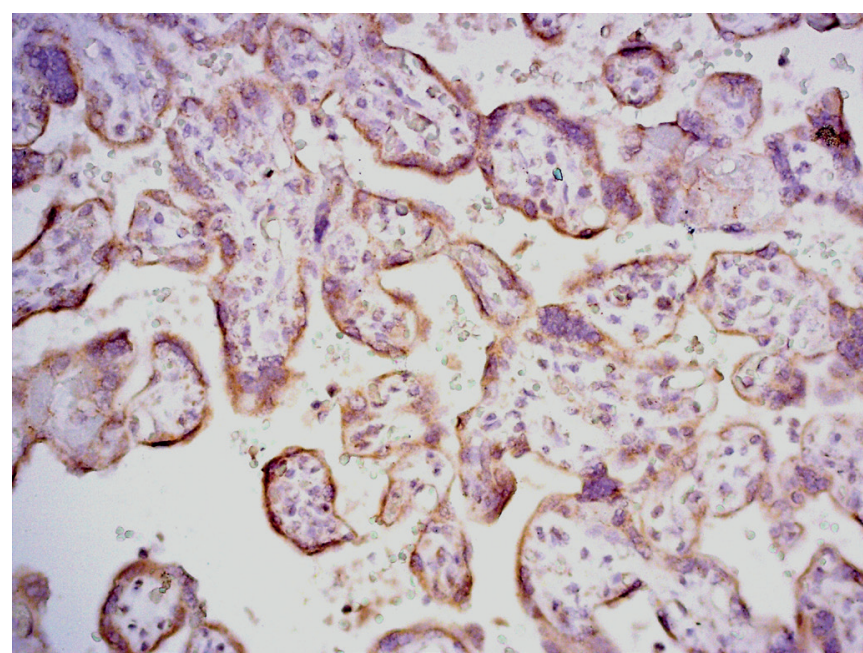

Fig. 4. Comparison group. In placental tissue there is positive expression of deposits on the villous surface, and in the areas of fibrinoid necrosis. Immunohistochemical reaction with MCA against VEGF, $\times 200$.

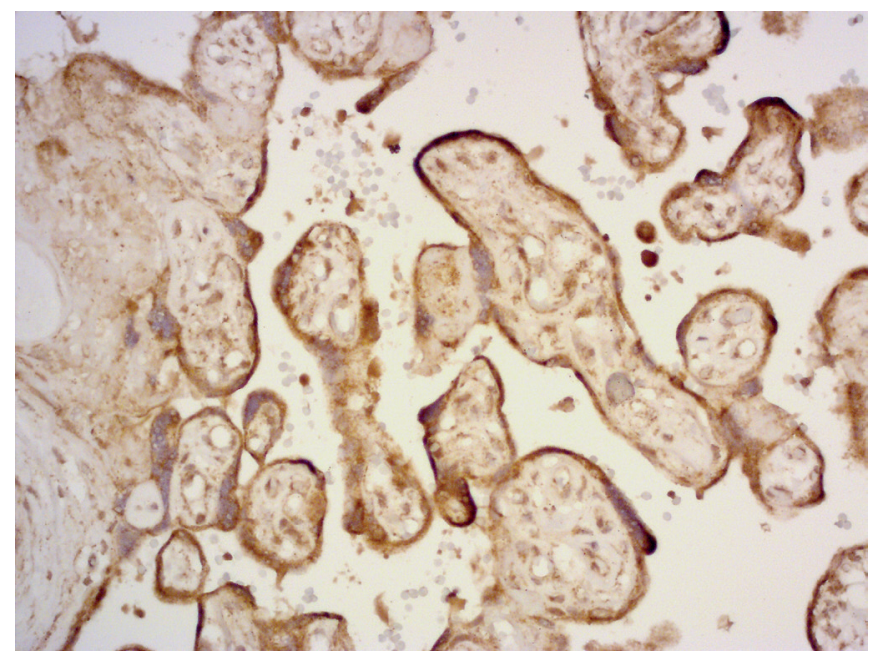

Fig. 6. Study group. Deposition of VEGF is found on the villous surface, in some areas becomes diffuse in the placental tissue and in the intervillous space. Immunohistochemical reaction with MCA against VEGF, $\times 200$. 
weight of the placentae were $3.1 \pm 0.4 \mathrm{~cm}$ and $467 \pm 12.3 \mathrm{~g}$. The central umbilical cord insertion sites were observed in 7 cases, the marginal in 3 . In one placenta the umbilical cord had two vessels (a single umbilical artery). The maternal surface of placentae had dark red color.

Microscopic examination demonstrated the edema of the Wharton's jelly and the signs of dysmucoidosis of varying severity in the umbilical cord tissue. The vessels of umbilical cord were full-blooded with the erythrocyte marginal standing phenomena. In the membranes tissue there were uneven thickening, swelling and uneven manifestations of dysmucoidosis with a varying severity, hemorrhages. In the placental tissue there was uneven maturation, represented by the areas of dysfunctional villi, which were characterized by the marked manifestations of dysmucoidosis, massive fields of fibrinoid necrosis and hemorrhages in the intervillous space. In some cases ischemic changes, calcium salts deposition were noted. Another characteristic feature of this group was the pronounced plethora of the intervillous space (hemorrhages) and villous vascular component, represented by disproportionate development, which is manifested by different vascular caliber or quantitative changes of vessels.

The immunohistochemical examinations with MCA against CD31+ revealed the enlargement of vascular endothelial cells (compared with the control group) with positive expression and increase of the staining intensity with a predominant score of 2 points.

The immunohistochemical examinations with MCA against VEGF demonstrated a marked expression of deposits in the vascular component of the villi and on the villous surface with staining intensity of 2 points (fig. 4).

Macroscopically the placentae of the study group had an oval shape in $60 \%$ of cases and round shape in $40 \%$ of cases. The weight and thickness of the placentae were $376.0 \pm 26.3 \mathrm{~g}$ and $2.1 \pm 0.3 \mathrm{~cm}$. The central umbilical cord insertion sites were observed in 8 cases, the marginal in 4. In two placentae the umbilical cord had two vessels (a single umbilical artery). The maternal surface of placentae had dark red color.

Pathomorphological examination of the placentae revealed more pronounced edema manifestations in umbilical cord tissues than in comparison group, which represented by partial stratification of the fibers of the vascular walls and dysmucoidosis in $90 \%$ of cases. Intracellular edema was observed in the tissue of fetal membranes, which represented by partial vacuolation of the cells, signs of dismucoidosis and small hemorrhages.

Placental tissue had more marked degenerative manifestations - in the form of fibrinoid necrosis, occupied larger areas, acquired drainage character and focal infarctions. The manifestations of dysmucoidosis and secondary ischemic changes were more pronounced. It was noted the vacuolation of the villous stroma. The study demonstrated the increased number of avascular villi and immature villi of small caliber with the phenomena of focal hyperplasia of syncytiotrophoblasts. The formation of daughter lateral small villi and free cells of the syncytiotrophoblast was observed in the intervillous space.
The immunohistochemical examinations with MCA against CD31+ showed increased optical density of vascular endothelial cells up to 2 points. In some areas there was staining intensity of 3 points with the expression on the villi surface and in their thickness (fig. 5).

The immunohistochemical study with MCA against VEGF revealed that expression level and optical density increased up to 2-3 points, in some areas deposits were found in the intervillous space, on the villi surface and in their thickness (fig. 6).

\section{DISCUSSION}

In the group of healthy mothers and term births with mature fetus the characteristic features were following: small areas of fibrinoid necrosis, isolated foci of dismucoidosis and small foci of hemorrhages into the intervillous space. There were umbilical cord tissues with mild or moderate swelling of Wharton's jelly, no abnormal changes in the tissue of the fetal membranes. The immunohistochemical examination with MCA against $\mathrm{CD} 31+$ showed absence of the expression of vascular endothelial cells or mild expression with optical density of 1 point. VEGF expression was overwhelmingly negative or slightly positive. These data correspond to the mature placenta with involuntary-degenerative changes and preserved function of the vascular component.

The placentae from HIV-positive women were characterized by significant increase of degenerative changes. The number and area of fibrinoid necrosis increased, and the manifestations of dysmucoidosis became more pronounced. It was found marked plethora of villous vessels, plethora and hemorrhage areas in the intervillous space, manifestations of neoangiogenesis and increasing the number of vessels. The immunohistochemical examination showed both quantitative and qualitative increase of CD31+ and VEGF expression; optical density reached 2 points. An increase in the optical density of CD3 + and VEGF expression indicates the impairment of placental trophic function due to degenerative changes of the microcirculatory bed vessels, namely the endothelial component.

Analyzing the data of HIV-positive parturient women and clinical manifestations of FGR we can say the following. The morphological picture demonstrated the changes inherent for comparison group and additionally manifestations of placental tissue immaturity, represented by heterogeneous architectonics of the placental tissue, presence of a great number of the dysfunctional villi, villi with the signs of hyperplasia of the stroma and syncytiotrophoblasts. Immunohistochemical study with MCA against CD31+ showed increasing the optical density and positive expression area up to 3 points. Immunohistochemical examination with MCA against VEGF revealed that the score of expression optical density was 2-3.

\section{CONCLUSIONS}

1. Morphological picture of the healthy mother placentae corresponds to the adaptive-compensatory changes of the mature placenta without pathological changes and with undisturbed function of the microcirculatory bed. 
2. In placentae from the group of HIV-positive parturient women the compensated chronic placental insufficiency with moderate manifestations of the vascular component affection was present in vast majority of cases.

3. The placentas of HIV-positive parturient women with FGR were characterized by a picture of subcompensated chronic placental insufficiency with the signs of placental tissue immaturity and moderate manifestations of vascular component dysfunction, or decompensated chronic placental insufficiency with marked manifestations of placental tissue immaturity and pronounced disorders of the tissue trophic due to vascular component.

4. Pathological changes inherent for the placentae of HIV-positive women especially associated with FGR indicate a marked dysfunction of the vascular component, which led to the placental dysfunction and FGR deve.

Prospects for further research. Further studies will focus on the identification of the correlation between clinical, pathomorphological and immunohistochemical parameters in order to develop more effective methods for prevention and prognosis the development of FGR.

\section{REFERENCES}

1. HIV infection in Ukraine. Newsletter No. 49. State Institution «Center of Public Health of the Ministry of Health of Ukraine», State Institution «Institute of Epidemiology and Infectious Diseases named after Gromashevsky National Academy of Medical Sciences of Ukraine», Kiev. 2018; 121. (Ua)

2. Ventskivskyi BM, Zabolotna AV, Zelinsky 00 , Senchuk AYa. Infections and pregnancy. Practical Guide. 2007; 364. (Ua)

3. Korchinskaya 00, Chernyak MM, Andrashchikova S, Zhultakova S, Ribarova L. Profilaktyka ta likuvannia platsentarnoi dysfunktsii u suchasnomu akusherstvi. [Prevention and treatment of placental dysfunction in modern obstetrics]. Ukraine. The nation's health. 2016;4(40): 171-175. (Ru)

4. Anoshina TM. Markers of vascular disorders in the placenta in HIV associated herpes virus infection. Experimental and clinical medicine. 2016;3(72): 113-118. (Ua)

5. Lazareva GA, Khuraseva AB, Klycheva OI Sovremennyj vzglyad na problemu fetoplaczentarnoj nedostatochnosti [A modern look at the problem of fetoplacental insufficiency]. Scientific statements. Series Medicine. Pharmacy. 2014;18(189)(27): 5-10. (Ru)

6. Zhivetska-Denisova AA, Vorobyova II, Tkachenko VB, Podolsky VV, Tyha VG. Platsenta yak dzerkalo vahitnosti (ohliad literatury). [The placenta as a mirror of pregnancy (literature review)]. Woman's health. 2019;3(139): 101-106. (Ua)

7. Degtyareva EA, Zakharova OA, Kufa MA, Kantemirov MG, Radzinski VE. Effektivnost prognozirovaniya i rannej diagnostiki zaderzhki rosta ploda [Efficiency of prediction and early diagnosis of fetal growth retardation]. Russian Journal of Perinatology and Pediatrics. 2018;63(6):37-45. (Ru)
8. Kolobov AV Morfogenez placzenty cheloveka i ee morfofunkczionalnoe sostoyanie pri patologi beremenosti [Morphogenesis of the human placenta and its morphofunctional condition in pregnancy pathologists]. Bulletin of St. Petersburg University. 2015;2: 5-18. (Ru)

9. Dabbs D. Diagnostic Immunohistochemistry. 4th ed. Philadelphia: Churchill Livingstone. 2014; 960.

10. De Young BR, Wick MR, Fitzgibbon JF, Sirgi KE, Swanson PE. CD31: an immunospecific marker for endothelial differentiation in human neoplasm. Appl Immunohistochem. 1993;1:97-100.

11. Golianovsky VA, Dyadik 00. Patomorfolohichni osoblyvosti poslidiv u vahitnykh iz zatrymkoiu rostu ploda [Pathomorphological features of placentae in pregnant women with fetal growth retardation]. Woman's health. 2019; 4(10): 50-54. (Ua)

12. Rosai and Ackerman's Surgical Pathology. Seven edition/edited by J. Rosai. Elsevierlnc. 2011; 1(2): 5-95.

13. Petrov SV, Raykhlin NT. Rukovodstvo po immunohistokhimicheskoj diagnostike opukholej cheloveka [Guide for immunohistochemical diagnosis of human tumors]. Kazan. 2012: 612. (Ru)

14. Delisser HM, DeLisser HM, Christofidou-Solomidou M, Strieter RM, Burdick MD, Robinson CS, Wexler RS, Kerr JS, Garlanda C, Merwin JR, Madri JA, Albelda SM. Involement of endothelial PECAM - 1/ CD31 in angiogenesis. Am J Pathol. 1997;151(3): 671-677.

\section{ORCID and contributionship:}

Serhii E. Savchenko - 0000-0003-3802-2187 A,B,D

Olena O. Dyadyk - 0000-0002-9912-4286 A,D,F

Kyrylo V. Chaika - 0000-0003-1738-8796 ${ }^{\mathrm{C}}$

Ludmila M. Onyshchyk - 0000-0001-5956-8192 A,B,D

Ludmila I. Vorobey - 0000-0002-8969-228X ${ }^{E}$

Roman V. Zhykharskyi-0000-0003-1146-5113 ${ }^{E}$

Volodymyr P. Bondaruk - 0000-0002-0292-0877 ${ }^{F}$

\section{Conflicts of interest:}

Authors declare no conflict of interest.

\section{CORRESPONDING AUTHOR Olena 0. Dyadyk}

Shupyk National Medical Academy of Postgraduate Education

9 Dorohozhytska str., 04112, Kyiv, Ukraine

e-mail: patholognew@ukr.net

Received: 23.05.2019

Accepted: 05.12.2019

A - Work concept and design, B - Data collection and analysis, C - Responsibility for statistical analysis, D-Writing the article, $\mathbf{E}$-Critical review, $\mathbf{F}$ - Final approval of the article 